\title{
INTERPRETASI INTERNATIONAL COURT OF JUSTICE (ICJ) PADA PASAL VI PERJANJIAN NON-PROLIFERATION TREATY 1968 (NPT)
}

\author{
Taufik Rachmat Nugraha \\ Fakultas Hukum, Universitas Padjadjaran \\ Jl. Raya Bandung Sumedang KM.21, Hegarmanah, Kec. Jatinangor, \\ Kabupaten Sumedang, Jawa Barat, 45363
}

\begin{abstract}
It has been 50 years since the Non-Proliferation Treaty was made by America, England, and the Soviet Union to prevent the nuclear arms race in the future. However, Article VI of NPT consisted of ambiguity and has sparked long-lasting debate questioning NPT electiveness. Article VI at least has been examining twice by the International Court of Justice (ICJ) in 1996 and 2014. Unfortunately, those examinations were unsatisfied regarding when Nuclear Weapon State (NWS) should cease and disarmament their nuclear weapon? If referring to "an early date," it should be done years long ago and not taking more than 50 years with pathetic achievement. Finally, this article will examine the current development of NWS using a normative juridical method according to existing nuclear regulation, ICJ Commentary, which resulting in a suggestion when NPT 1968 parties should fulfil their obligation under Art VI NPT 1968.
\end{abstract}

Key words: NPT 1968, Nuclear Weapon, ICJ Commentary, Interpretation of Treaty.

\begin{abstract}
Abstrak
Sudah 50 tahun Non-Proliferation Treaty 1968 (NPT) dibuat oleh Amerika Serikat, Inggris, dan Uni Soviet sebagai pencegahan meletusnya perang menggunakan senjata nuklir di masa depan. Akan tetapi, dalam NPT sendiri khususnya Pasal VI menyimpan ambiguitas dan menimbulkan perdebatan selama bertahun-tahun bagaimana efektifitas isi dari NPT. Pasal VI NPT setidaknya pernah diuji dua kali pada tahun 1996 dan 2014, namun sayangnya belum membuahkan hasil yang memuaskan mengenai kapan senjata nuklir dari negara peserta NPT 1968 harus benarbenar dilucuti. Jika melihat kata-kata "an early date" seharusnya pelucutan senjata nuklir sudah beres sejak lama dan tidak memakan waktu hingga lebih dari 50 tahun dengan kemajuan yang menyedihkan. Penelitian yuridis normatif mengelaborasi peraturan tentang kesenjataan nuklir termasuk komentar ICJ pada Pasal VI fakta yang masih terjadi hingga saat ini, dan memberikan saran kapan seharusnya pemenuhan isi Pasal VI dilakukan oleh negara peserta untuk mencegah meletusnya perang nuklir di masa depan.
\end{abstract}

Kata Kunci: NPT 1968, Senjata Nuklir, Komentar ICJ. Interpretasi Perjanjian. 


\section{Latar Belakang.}

Senjata nuklir dipakai pertamakali pada masa perang dunia ke dua oleh Amerika Serikat ketika menyerang Jepang, yakni tepatnya di Nagasaki dan Hiroshima. Pembuatan senjata nuklir pertama kali diinisiasikan oleh presiden Amerika saat itu Harry S. Truman melalui instruksipresiden ditahun 1942. Setelahperang dunia usai, pihak sekutu sebagai pemenang perang mulai serius untuk mengembangkan senjata nuklir ke tahap berikutnya, berbagai pengetesan pun dilakukan oleh Uni Soviet, Britania Raya dan Amerika Serikat dari kurun waktu tahun 1949 hingga tahun 1964. Selama periode pengembangan tersebut terlihat hasil yang cukup mencengangkan, bahwa senjata nuklir dapat memiliki daya yang lebih besar daripada bom yang dijatuhkan di Nagasaki dan Hiroshima pada tahun 1945. Selanjutnya hal yang perlu diingat adalah senjata nuklir memiliki tiga prinsip kerugian yakni, senjata nuklir memiliki efek yang merusak dalam jangka pendek dan panjang, tidak ada negara atau organisasi manapun yang sanggup memenuhi kebutuhan kemanusiaan setelah ledakan nuklir, dan efek senjata nuklir tidak mengenal batas negara. ${ }^{1}$

Berangkat dari hasil pengembangan tersebut muncul kekhawatiran jika senjata nuklir yang begitu dahsyatnya dapat digunakan sebagai senjata perang maupun memicu perang. Karena pada masa pasca perang dunia ke-II muncul dua kekuatan yang saling bertolak belakang yaitu Uni Soviet dan Amerika, dan kedua-duanya merupakan negara pengembang senjata nuklir. Pada tahun 1968 pemerintah Amerika Serikat, dan Uni Soviet memiliki inisiatif untuk mencegah perang nuklir terjadi, yaitu dengan mengusulkan Non-Proliferation Treaty (NPT selanjutnya). ${ }^{2}$

NPT dimaksudkan sebagai sebuah perjanjian yang menekankan pentingnya perlucutan senjata nuklir khususnya bagi negara yang pada saat itu sedang mengembangkan nuklir sebagai senjata agar tidak terjadi bencana nuklir. NPT berisikan 11 klausul yang mengatur penghapusan serta perlucutan senjata nuklir, dari klausulklausul tersebut ada salah satu klausul yang menimbulkan perdebatan diantara para pihak, yaitu Pasal VI dari perjanjian tersebut, yang isinya:

"Each of the Parties to the Treaty undertakes to pursue negotiations in good faith on effective measures relating to cessation of the nuclear arms race at an early date and to nuclear disarmament, and on a treaty on general and complete disarmament under strict and effective international control."

Klausul tersebut menimbulkan polemik bagi para pihak dalam perjanjian tersebut, apakah klausul tersebut dikategorikan dalam pactum de negotiando atau pactum

1 Rebecca Davis Gibbons, "The Humanitarian Turn in Nuclear Disarmament and the Treaty on the Prohibition of Nuclear Weapons," The Nonproliferation Review 25, no. 1-2 (2 Januari 2018): 11-36, p. 20.

2 Paul M Kiernan, “DISARMAMENT' UNDER THE NPT: ARTICLE VI IN THE 21ST CENTURY,” Michigan State International Law Review 20, no. 2 (2012):20, p .384. 
de contrahendo. Pada tahun 1996 ICJ

(International Court of Justice) pernah mengeluarkan putusan terkait legalitas penggunaan senjata nuklir, pada putusannya ICJ menyebutkan terkait dengan Pasal VI dari NPT memaksa Negara peserta untuk melakukan hal yang lebih daripada sekedar "aksi" namun juga harus ada "hasil" akhir sebagai kewajiban. Pada hasilnya hakim dengan suara bulat memutuskan "here exists an obligation to pursue in good faith and bring to a conclusion negotiation leading to nuclear disarmament in all its aspects under strict and effective international control." ${ }^{3}$

Dengan demikian putusan ICJ tersebut mengisyaratkan bahwa Pasal VI tersebut merupakan perjanjian yang tidak dapat dinegosiasikan dimasa depan (Pactum de Negotiando) melainkan, kesepakatan untuk mencapai suatu pemahaman yang komprehensif (Pactum de Contrahendo). ${ }^{4}$ Walaupun sudah ada pendapat dari ICJ tetap saja isi dari Pasal VI ini tetap menjadi perdebatan, terutama diantara negara pemegang senjata nuklir, mereka berkilah bahwa apa yang dimaksud dalam Pasal VI harus merujuk kepada isi dari pada Pasal IV tentang "good faith", NWS (Nuclear Weapon
State) berpendapat bahwa mereka sudah melakukan apa yang diamanatkan Pasal VI dengan melakukan itikad baik, berupa pengurangan jumlah hulu ledak. Selanjutnya walaupun ICJ sudah memberikan komentar terkait NPT namun tidak secara spesifik memberikan saran pada Pasal VI yang juga mungkin pertanyaan semacam itu bersifat ultra vires..$^{5}$

Pemerintah Inggris melaporkan apa yang mereka sebut dengan pencapaian itikad baik adalah seperti hal diatas, yaitu pengurangan hulu ledak nuklir sebanyak 120 buah pada 2015 dari 160 buah di tahun 2010, dan Hulu Ledak yang siaga sebanyak 40 buah dari 48 buah di tahun $2010 .{ }^{6}$ Pada tahun 1992 pemerintah Britania Raya membuat satu program kekhususan nuklir di dalam departemen pertahanannya, yaitu disebut dengan "Tridentine Nuclear Program", program ini menghasilkan 4 kapal selam kelas Vanguard yang masing-masing membawa 8 misil dan 40 hulu ledak nuklir disetiap misilnya. $^{7}$

Keadaan ini sangat kontras terhadap isi didalam perjanjian Non-Proliferasi, di Pasal VI bahwa Negara peserta seharusnya dapat menghentikan pengembangan senjata nuklir

3 David Simon, "Article Vi of The Non-Proliferation Treaty Is a Pactum De Contrahendo And Has Serious Legal Obligation by Implication,” Journal of International Law \& Policy II (2005), https://www.law.upenn. edu/journals/jil/jilp/articles/21_Simon_David.pdf.

4 Ibid.

5 Christopher A. Ford, "DEBATING DISARMAMENT: Interpreting Article VI of the Treaty on the NonProliferation of Nuclear Weapons," The Nonproliferation Review 14, no. 3 (November 2007): 401-28.

6 Ministry of Defence. "The UK's nuclear deterrent: what you need to know". Available at: https://www.gov. uk/government/publications/uk-nuclear-deterrence-factsheet/uk-nuclear- deterrence-what-you-need-to-know diakses 18 October 2018

7 "The UK's nuclear deterrent: what you need to know," 2018, https://www.gov.uk/ government/publications/uk-nuclear-deterrence-factsheet/uk-nuclear- deterrence-what-you-need-to-know. 
dan harus menghapus senjata nuklir dari program pertahanannya secara implisit. Seperti yang disebutkan diatas bahwa pemerintah Britania Raya hingga saat ini masih melakukan pemeliharaan dan pengembangan terhadap senjata nuklir, walaupun mereka mengklaim bahwa sudah terjadi penurunan jumlah hulu ledak dari tahun ke tahun sebagai bagian dari upaya good faith yang berusaha dipenuhi oleh pemerintah Britania Raya. Selain itu, pemerintah Britania Raya dan Negara yang masih memelihara senjata nuklir, khususnya pada Negara peserta NPT mengabaikan term “An Early Date” jika dilihat bahwa pada terminologi tersebut terdapat ambiguitas, yang akan menimbulkan pertanyaan kapan seharusnya Negara peserta pemilik senjata nuklir memenuhi isi dari NPT tersebut.

Tidak adanya patokan resmi kapan seharusnya Negara pemilik senjata nuklir melakukan pelucutan dan penghapusan program senjata nuklir tidaklah jelas, ini menimbulkan multi tafsir, terhadap terminologi tersebut, tetapi yang dimaksud "sesegera mungkin" adalah tidak lebih dari 20 tahun, patut dipertanyakan apakah jika lebih dari tenggat waktu tersebut perjanjian ini masih relevan.

Melihat hal tersebut artikel ini akan menekankan apakah praktik Nuclear Weapon State sudah sesuai dengan implementasi dari perjanjian yang memiliki klausul yang ambigu didalamnya, khususnya yang berkaitan dengan keamanan dunia dan perdamaian. Sebagai pembahasan, penelitian ini menggunakan metode juridis normatifakan mengkaji interpretasi ganda Pasal VI NPT dan mengelaborasikannya dengan fakta saat ini di negara dengan senjata nuklir (nuclear weapon state).

\section{A. Praktik Negara Inggris dan Amerika dalam Pemeliharaan Senjata Nuklir.}

\section{Praktik Inggris.}

Didalam faktanya negara pemilik senjata nuklir hingga saat ini masih memiliki, menyimpan, dan mengembangkan senjata nuklir. Sebagai contoh menurut data yang ada pada tahun 2015 tentang seberapa banyak hulu ledak nuklir yang masih dimiliki oleh pemerintah Britania Raya adalah sebanyak 120 buah pada 2015 dari 160 buah di tahun 2010, dan Hulu Ledak yang siaga sebanyak 40 buah dari 48 buah di tahun $2010 .{ }^{8}$ Pada tahun 1992 pemerintah Britania Raya membuat satu program kekhususan nuklir didalam departemen pertahanannya, yaitu disebut dengan "Tridentine Nuclear Program" dalam UK Nuclear Deterrence Policy (UNDP), program ini mengahsilkan 4 kapal selam kelas Vanguard yang masing-masing membawa 8 misil dan 40 hulu ledak nuklir disetiap misilnya, berdasarkan perhitungan setiap hulu ledak berkekuatan hampir tujuh kali lebih kuat dibandingkan bom Hiroshima dan Nagasaki. ${ }^{9}$ 
Biaya yang digelontorkan oleh pemerintah Britania Raya mencapai \$38.5 Miliar untuk memperbaharui program tridentin untuk 30 tahun ke depan. Dan dengan alasan bahwa ini adalah upaya pencegahan terhadap ancaman yang mungkin dihadapi oleh Britania Raya disuatu saat.

"Therefore, the government is committed to maintaining the UK's independent nuclear deterrent to deter the most extreme threats to our national security and way of life, now and in the future."

Selain itu mengikuti pernyataan dalam UNDP bahwa penggunaan senjata nulklir inggris selain bagian dari self defence juga sebagai wujud nyata perlindungan terhadap negara anggota North Atlantic Treaty Organization (NATO) ${ }^{10}$ selain itu dalam salah satu prinsip dalam UNDP adalah adanya ambiguitas yang tetap dijlaksanakan sebagai upaya pencegahan terhadap serangan nuklir, kapan dan dalam situasi apa senjata nuklir dapat digunakan, ${ }^{11}$ ini sebagai upaya untuk memastikan bahwa penggunaan senjata nuklir dalam situasi dan kondisi yang tepat.

Keadaan ini sangat kontras terhadap isi di Pasal VI NPT, bahwa Negara peserta seharusnya dapat menghentikan pengembangan senjata nuklir dan harus menghapus senjata nuklir dari program pertahanannya secara implisit. Seperti yang disebutkan di atas bahwa pemerintah Britania Raya hingga saat ini masih melakukan pemeliharaan dan pengembangan terhadap senjata nuklir, walaupun mereka mengklaim bahwa sudah terjadi penurunan jumlah hulu ledak dari tahun ke tahun sebagai bagian dari upaya good faith yang berusaha dipenuhi oleh pemerintah Britania Raya.

Tetapi selain itu pemerintah Britania Raya dan Negara yang masih memelihara senjata nuklir, khususnya pada Negara peserta penandatanganan NPT mengabaikan term "An Early Date" jika dilihat bahwa pada terminologi tersebut terdapat ambiguitas, yang akan menimbulkan pertanyaan "kapan seharusnya Negara peserta pemilik senjata nuklir memenuhi isi dari NPT tersebut"?

Tidak adanya patokan resmi kapan seharusnya Negara pemilik senjata nuklir melakukan pelucutan dan penghapusan program senjata nuklir tidaklah jelas, ini menimbulkan multi tafsir, terhadap terminologi tersebut, tetapi yang dimaksud "sesegera mungkin" adalah tidak lebih dari 20 tahun, patut dipertanyakan apakah jika lebih dari tenggat waktu tersebut perjanjian ini masih relevan.

Sehingga sebenarnya tidak ada alasan bagi Negara pemilik senjata nuklir menunda penghapusan program nuklir mereka, apalagi jika alasan utama mereka adalah

10 Ministry of Defence, "Policy paper 2010 to 2015 government policy: UK nuclear deterrent," Government of UK, 2015, https:/www.gov.uk/government/publications/2010-to-2015- government-policy-uk-nucleardeterrent/2010-to-2015-government-policy-uk-nuclear-deterrent.

11 Brian Drummond, “UK Nuclear Deterrence Policy: An Unlawful Threat of Force,” Journal on the Use of Force and International Law 6, no. 2 (3 Juli 2019): 193-241. 
untuk melindungi kedaulatan Negara dari ancaman jika merujuk apa yang dilakukan oleh pemerintah Britania Raya maka kita seharusnya bisa merujuk itu kepada peraturanperaturan internasional lain yang melarang penggunaan senjata pada masa perang yang menyebabkan kerusakan yang tidak perlu dan penderitaan yang berkepanjangan, seperti yang dicantumkan didalam Protokol Tambahan I 1977 pada Pasal 35 (2) \& (3) dan pada Pasal 55: (1) "It is prohibited to employ weapons, projectiles and material and methods of warfare of a nature to cause superfluous injury or unnecessary suffering. " (2) "It is prohibited to employ methods or means of warfare which are intended, or may be expected, to cause widespread, long-term and severe damage to the natural environment."

"Care shall be taken in warfare to protect the natural environment against widespread, long-term and severe damage This protection includes a prohibition of the use of methods or means of warfare which are intended or may be expected to cause such damage to the natural environment and thereby to prejudice the health or survival of the population." ${ }^{\text {"12 }}$

\section{Praktik Amerika.}

Amerika sebagai negara yang pertama kali memanfaatkan nuklir sebagai senjata pada perang dunia ke-2 dan sebagai negara inisiator msih memelihara dan mengembangkan program kesenjataan nuklir mereka. Amerika sebagai salah satu negara inisiator NPT beranggapan bahwa perang nuklir di masa depan tidak boleh terjadi, terlebih Uni Soviet memiliki kapasitas yang sama untuk mengembangkan senjata nuklir dan menempatkannya di seluruh wilayah blok timur Eropa. ${ }^{13}$ Sedari tahun 1945 Amerika telah melakukan uji coba senjata nuklir sebanyak 1.045, termasuk di dalamnya lokasi test di Bikini Atoll. ${ }^{14}$

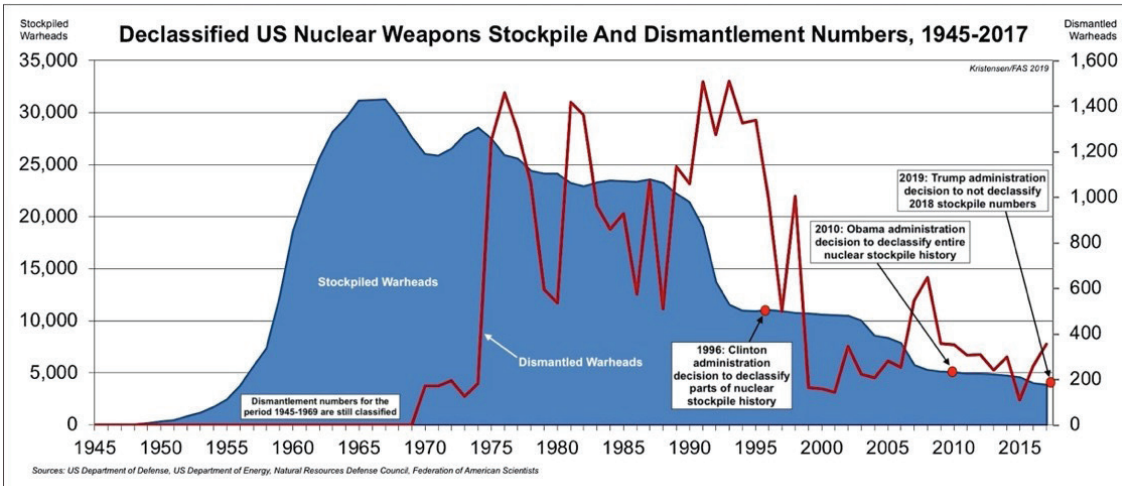

Gambar 1: Jumlah hulu ledak nuklir yang dimiliki oleh Amerika Serikat

Sumber : https://fas.org/blogs/security/2019/04/stockpilenumbersecret/

12 International Committee of Red Cross, "Protocol Additional to the Geneva Conventions of 12 August 1949 , and relating to the Protection of Victims of International Armed Conflicts (Protocol I), 8 June 1977.," Treaties, States Parties and Commentaries, t.t., https://ihl-databases.icrc.org/ihl/WebART/470-750070?OpenDocument.

13 Lewis A. Dunn, "Negotiating and Sustaining the Non-Proliferation Treaty: Challenges and Lessons for USRussia Cooperation," Adelphi Series 56, no. 464-465 (November 2016): 117-34.

14 NTI, “U.S Nuclear Overview," Nuclear Threat Initiative, 2019, https://www.nti.org/learn/ countries/united-states/. 
Selanjutnya, selama masa pertukaran data nuklir (senjata) antara Amerika dan Uni Soviet berlangsung ditengah-tengah ketegangan akan krisis nuklir, terlebih lagi pada saat itu krisis misil kuba baru saja selesai, sebagai langkah antisipatif Amerika melakukan instalasi senjata nuklir di beberapa tempat strategis Bersama (NATO) sebagai bagian strategi counterpart terhadap Uni Soviet. ${ }^{15}$

Jika melihat grafik yang disediakan oleh Department of Defense (DoD) jumlah hulu ledak amerika serikat mengalami kenaikan yang signifikan yaitu mencapai 31.255 di tahun $1967 .{ }^{16}$ Selanjutnya jika dilihat dengan seksama, jumlah hulu ledak yang dimiliki oleh Amerika turun drastis setelah selesainya masa perang dingin yaitu "hanya" tersisa sebanyak kurang lebih 10.000 buah, dan jumlah hulu ledak yang dibongkar mengalami kenaikan drastis hingga angka 30.000.

Selanjutnya, berdasarkan data dari DoD jumlah hulu ledak nuklir yang dimilki oleh Amerika hingga tahun 2017 berjumlah sebanyak 3,822, dan jumlah hulu ledak nuklir yang dibongkar sebanyak $354 .{ }^{17}$ Kemudian berdasarkan data dari DoD sebaran senjata nuklir untuk penggunaan strategis yaitu sebanyak 230 senjata nuklir dan 150 diantaranya berupa bom berjenis B-61 (dengan kapasitas ledakan terdiri dari 0,5 kiloton hingga 50 kiloton) yang ditempatkan di lima fasilitas penyimpanan senjata nuklir di lima negara di benua Eropa (NATO) seperti; Jerman, Turki, Belanda, Belgia, dan Italia. ${ }^{18}$ Saat ini fasilitas-fasilitas penyimpanan tersebut sudah ditingkatkan kapabilitasnya untuk menyimpan jenis bom B-61 seri $12 .{ }^{19}$

Jika ditelaah dengan seksama Amerika sebagai negara inisiator seharusnya melakukan perlucutan dan pengehntian program nuklir untuk kepentingan senjata dan militer sejak NPT dibuat dan entry into force di tahun 1970. Namun perlu diingat bahwa tidak semua NWS pada masa itu terikat dengan perjanjian tersebut, seperti halnya Perancis yang baru meratifikasi NPT di tahun $1992 .{ }^{20}$ Sehingga dalam konteks perlucutan senjata dalam sudut pandang Amerika akan sulit secara politik jika negara-negara lain tetap memelihara dan mengembangkan nuklir sebagai bagian dari stategis militer. Juga ketegangan antara Russia dan Merika saat ini yang sebetulnya masih berlangsung dalam konteks keamanan global.

Namun, dalam satu dekade kebelakang ini terjadi kemajuan antara Amerika dan Russia khususnya membuat suatu program pengurangan senjata strategis, atau dikenal sebagai, New Strategic Arms Reduction Treaty

15 Lewis A. Dunn, loc.cit.

16 NTI, "U.S Nuclear Overview."

17 Hans M. Kristensen, "Despite Rhetoric, US Stockpile Continues to Decline," Federation of American Scientist, 2018, https://fas.org/blogs/security/2018/03/stockpile-reduction/.

18 Hans M. Kristensen dan Matt Korda, “Tactical Nuclear Weapons, 2019," Bulletin of the Atomic Scientists 75, no. 5 (3 September 2019): 252-61.

19 Ibid.

20 Or Rabinowitz, “'When Pigs Fly’: Britain, Canada and Nuclear Exports to Israel, 1958-1974,” Diplomacy \& Statecraft 30, no. 4 (2 Oktober 2019): 707-28. 
(START). Dalam perjanjian bilateral tersebut disebutkan adanya pembatasan terhadap jumlah senjata strategis dan yaitu maksimal sebanyak 700 Intercontinentall Ballistic Missile (ICBM) dan Submarine Launched Ballistic Missile (SLBM), kemudian jumlah maksimal senjata strategis yang menggunakan hulu ledak nuklir yakni 1.550 buah pada ICBM dan SLBM, dan 800 buah pada kategori senjata strategis yang tidak dikerahkan (cadangan). ${ }^{21}$ Dalam perjanjian tersebut juga disebutkan bukan hanya pembatasan senjata strategis (termasuk nuklir) di dalamnya, namun juga transparansi mengenai kapasitas masingmasing pihak, hingga hari ini sudah ada 19.852 pertukaran notifikasi antara Amerika dan Rusia.

Hanya saja, START sedari awal memang bukan dibuat untuk menghapuskan senjata nuklir secara total seperti apa yang disampaikan dalam Pasal VI NPT, START hanya sebagai katalisator untuk pembatasan senjata nuklir Amerika dan Rusia, dalam hal ini, walaupun secara kuantitas senjata nuklir amerika menurun namun, terdapat peningatan kualitas dan kapabilitas seperti halnya pembuatan bom B-61 seri 12, hal yang sama seperti yang dilakukan oleh Inggris melalui program Tridentine.
B. Gugatan Republik Kepualauan Marshall (RKM) Kepada ICJ Terkait Kewajiban Pemenuhan isi dari Non-Proliferation Treaty 1968.

Pada tahun 2014 Republik Kepulauan Marshall (RKM) mengajukan gugatan kepada ICJ atas NNWS baik peserta NPT maupun non peserta NPT. Perlu diingat bahwa RKM selama era perang dingin wilayahnya kerap kali dijadikan lokasi pengetesan senjata nuklir oleh Amerika serikat dan Inggris tepatnya di Bikini Atoll. Hingga saat ini efek sisa dari percobaan itu meninggalkan sampah radioaktif yang masih terasa hingga saat ini. Pada dasarnya sampah radioaktif tidak akan bisa hilang dalam waktu singkat, yakni membutuhkan waktu ratusan hingga ribuan tahun agar sisa-sisa dari radioaktif benar-benar hilang seutuhnya. Pada tahun 2010 sebuah kapal nelayan Jepang melintasi wilayah perairan sekitar Bikini Attol di kepulauan Marshall Island. Setelah mereka kembali ke Jepang beberapa diantara ABK merasakan sakit dan mereka didagnosis terkena kanker dan meninggal dunia ${ }^{22}$ hanya dalam waktu beberapa bulan setelah mereka melewati Bikini Attol dan sisanya masih bisa bertahan hingga bertahun-tahun kemudian. Melalui kasus tersebut hendaknya penghapusan penggunaan senjata nuklir adalah menjadi sebuah keharusan.

21 Hans M. Kristensen dan Matt Korda, “United States Nuclear Forces, 2020," Bulletin of the Atomic Scientists 76, no. 1 (2 Januari 2020): 46-60. Lihat juga pada keterangan di Department of State (DoS) https://www.state. gov/new-start/

22 Agence France, "The Guardian 'Bikini Atoll Nuclear Test: 60 Years Later and Islands Still Unliveable," News Magazine, The Guardian, 2014, https://www.theguardian.com/world/2014/ mar/02/bikini-atoll-nuclear-test-60-years. 
RKM memasukan gugatan atas Inggris, Perancis, Amerika, Russia, Cina, India, Pakistan, Israel. ${ }^{23}$ RKM memiliki alasan tersendiri bahwa negara-negara tersebut hingga saat ini masih memelihara senjata nuklir dan mengembangkannya yang bertentangan dalam Pasal VI NPT dan hukum kebiasaan internasional. ${ }^{24}$ Namun hanya gugatan terhadap Inggris, India, dan Pakistan yang berlanjut karena hanya ketiga negara tersebut yang membuat optional declarations sesuai dalam ketentuan Pasal 36 ayat 2 dari statuta ICJ.

Selanjutnya, ICJ tidak melihat adanya suatu permasalahan atau sengketa dalam gugatan yang diajukan oleh RKM kepada Inggris, India, dan Pakistan, maka dampak dari sudut pandang ICJ tersebut adalah gugatan RKM tidak dilanjutkan dikarenakan Lack of Jurisdiction. ${ }^{25}$ Namun, ICJ tetap mengakui bahwa senjata nuklir adalah senjata yang dapat menyebabkan kerusakan katastropik yang dapat mengancam generasi masa depan, juga efek dari senjata nuklir tidak mengenal antara objek sipil dan militer, sehingga senjata nuklir dalam hal ini dapat menyebabkan pelanggaran lain yakni berupa unnecessary suffering dan prinsip proportionality yang bersifat sebagai prinsip utama dalam hukum humaniter.

\section{Interpretasi Pada Vienna Convention Law of Treaties 1969}

Konvensi Wina tentang hukum perjanjian internasional tahun 1969 (Selanjutnya disebut Konvensi Wina 1969) merupakan produk awal daripada International Law Commission (ILC) yang dibentuk pada tahun 1947, yang ditugaskan untuk pengembangan hukum internasional dan melakukan kodifikasi hukum, topik utama yang menjadi pembahasan mula-mula adalah mengenai hukum perjanjian internasional yang mulai dibahas pada tahun 1949. ${ }^{26}$ Konvensi Wina sendiri selesai dibuat pada tahun 1966 dan terbuka untuk ditandatangan pada tahun 1969 dan berlaku mulai 27 Januari 1980.27 Ruang lingkup yang dibahas didalam Konvensi Wina 1969 mencakup prosedur pembuatan perjanjian, menjalankan perjanjian dan pengakhiran perjanjian, yang dimaksudkan disini ialah perjanjian yang dibuat antara Negara dan Negara sebagai subjek hukum internasional. ${ }^{28}$

Perjanjian internasional merupakan hal yang umum terjadi yang melandasi hubungan antar negara-negara, dan negara dengan subjek hukum internasional. "Perjanjian internasional adalah perjanjian yang diadakan antara anggota masyarakat bangsa-bangsa

23 International Court of Justice, "Obligations Concerning Negotiations Relating to Cessation of the Nuclear Arms Race and to Nuclear Disarmament (Marshall Islands v. United Kingdom)," Summary of the Judgment of 5 October 2016 (The Hague: International Court of Justice, 5 Oktober 2016), https://www.icj-cij.org/files/ case-related/160/19228.pdf.

24 Ibid.

25 Namun, perlu diingat bahwa pada putusan tersebut terdapat dissenting opinion dari wakil presiden ICJ Yusuf; Judges Bennouna, Cançado Trindade, Sebutinde, Robinson, Crawford; Judge ad hoc Bedjaoui.

26 Anthony Aust, Modern Treaty Law and Practice, Second Edition (Cambridge: Cambridge University Press, 2007).

27 Ibid.

28 Ibid. 
dan bertujuan untuk mengakibatkan akibat hukum tertentu.’29 Perjanjian internasional ada yang bersifat bilateral yaitu perjanjian dengan hanya dua pihak dan multilateral yaitu perjanjian dengan banyak pihak.30 Perjanjian internasional sendiri merupakan praktik yang sudah sangat lama dijalankan oleh negaranegara di dunia untuk menghasilkan suatu kesepakatan tertentu, contohnya perjanjian yang cukup terkenal yang membagi bumi atas dua bagian yaitu perjanjian Tordesilhas antara kerajaan Spanyol dan Portugal ditahun 1497 yang ditujukan salah satunya untuk meredam konflik antara pelaut Portugis dan Spanyol.31

Selanjutnya perjanjian internasional mulai diatur mekanismenya dalam Konvensi Wina tahun1969 tentang perjanjian internasional. Perjanjian menurut Konvensi ialah tersebut:

"an international agreement concluded between states in written form and governed by international law, whether embodied in a single instrument or in two or more related instruments and whatever its particular designation”. Konvensi Wina nampaknya hanya mengatur mengenai perjanjian yang tertulis. Meskipun demikian, hukum internasional juga mengakui kekuatan hukum perjanjian lisan (oral treaties), walaupun pada praktiknya Negara-negara sangat jarang membuat perjanjian internasional secara lisan.
Perjanjian internasional pada hakikatnya merupakan sumber hukum internasional yang utama adalah instrumen-instrumen yuridis yang menampung kehendak dan persetujuan negara atau subjek hukum lainnya untuk mencapai tujuan bersama. Persetujuan bersama yang dirumuskan dalam perjanjian tersebut merupakan dasar hukum internasional untuk mengatur negara-negara di dunia ini.32 Menekankan kata "tujuan bersama"mestilah ada suatu cita-cita yang hendak dicapai dengan pembuatan perjanjian internasional tersebut, tidak terkecuali dalam pembuatan perjanjian yang berhubungan dengan keamanan dunia. Interpretasi merupakan hal yang wajar bagi setiap perjanjian multilateral yang telah dihasilkan, tidak terkecuali pada Pasal VI dari NPT yang sedari pembuatannya memangsudah menimbulkan berbagai macam interpretasi, hal ini berkaitan erat dengan bagaimana NWS melakukan kewajibannya terhadap isi dari NPT khususnya Pasal VI. Dalam VCLT 1969 interpretasi terdapat pada Pasal 31. Bahwa setiap interpretasi harus dilakukan dalam maksud itikad baik. Interpretasi sendiri memiliki tujuan untuk mempelajari arti yang sebenarnya dan isi dari peraturan-peraturan hukum yang berlaku. ICJ sendiri menyebutkan bahwa interpretasi merupakan isi dan arti yang sebenarnya dari suatu perjanjian.33 Dengan

29 Mochtar Kusumaatmadja dan Etty R. Agoes, Pengantar Hukum Internasional, Edisi kedua (Bandung: Pt. Alumni, 2012).

30 Ibid.

31 The Editor of Encyclopedia Britannica, "Treaty of Tordesilhas", https://www.britannica. com/event/Treaty-of-Tordesillas accesed on 15 June 2019.

32 Boer Mauna, Hukum Internasional Pengertian Peranan dan Fungsi dalam Era Dinamika Global, Edisi Kedua (Bandung: Pt. Alumni, 2015). hlm. 84

33 Ibid. 
semakin banyaknya perjanjian internasional yang dihasilkan dimasa modern kini, sulit untuk menghindari adanya isi dari perjanjian yang menimbulkan interpretasi ganda. Maka dengan demikian interpretasi memang diperlukan untuk menafsirkan makna-makna yang sesungguhnya yang hendak dicapai oleh perjanjian tersebut. Hal tersebut sebenarnya sudah diatur didalam Pasal 31 VCLT ayat I yang berbunyi:

" A treaty shall be interpreted in good faith in accordance with the ordinary meaning to be given to the terms of the treaty in their context and in light of object and purpose"

"The context of the purpose of the interpretation of a treaty shall comprise, in addition to the text, including its preamble and annexes: (1) any agreement relating to the treaty which was made between all the parties in connection with the conclusion of the treaty. (2) any instrument which was made by one or more parties in connection with the conclusion of the treaty and accepted by the other parties as an instrument related to the treaty."

Pasal 31 dari VCLT seharusnya dilihat dalam satu kesatuan utuh dan sebagai cara tambahannya merujuk kepada Pasal 32 VCLT, dengana artian bahwa aturan dalam Pasal 31 VCLT merupakan aturan aturan yang memaksa dalam sebuah penginterpretasian, sedangkan dalam Pasal 32 aturan-aturan tambahan yang tidak diwajibkan dalam penginterpretasian. Dengan demikian dalam Pasal 31 VCLT terdapat aturan umum yakni, suatu perjanjian harus diinterpretasikan dalam prinsip good faith sesuai dengan pengertian yang lazim diberikan pada istilah-istilah dari perjanjian dalam konteks dan dipandang dari maksud dan tujuannya. Konteks yang dimaksud disini ialah suatu interpretasi yang terdapat dalam suatu perjanjian harus mencakup tambahantambahan pada teks perjanjian tersebut termaksud didalamnya bagian mukadimah dan lampiran-lampiran yaitu. ${ }^{34}$

1. "Setiap persetujuan berkenaan dengan perjanjian yang dibuat antara semua pihak berkaitan dengan penutupan perjanjian."

2. "Setiap instrumen yang dibuat oleh satu atau lebih pihak berkenaan dengan penutupan perjanjian dan diterima oleh pihak-pihak lain sebagai suatu instrument yang berhubungan dengan perjanjian."

Selanjutnya harus diperhatikan juga Bersama-sama dengan konteks:

1. Setiap persetujuan antara pihak mengenai interpretasi perjanjian international atau aplikasi ketentuannya

2. Setiap praktik kemudian dalam penerapan perjanjian yang membentuk persetujuan antara pihak mengenai interpretasinya.

3. Setiap ketentuan hukum internasional yang relevan yang dapat dipakai dalam hubungan antara pihak-pihak.

Suatu pengertian khusus dapat diberikan pada suatu istilah jika para pihak menetapkan maksudnya demikian. Pada Pasal 32 yang 
membahas mengenai cara- cara tambahan dalam peinterpretasian terhadap perjanjian internasional yaitu adalah sebagai usaha lain yang dapat dipakai sebagai cara tambahan pada interpretasi perjanjian termaksud preparatory work dan juga keadaan pada bagian penutupnya, supaya memperkuat pengertian penerapan Pasal 31 VCLT atau untuk menetapkan penegrtian interpretasi dalam Pasal 31 memberikan arti ganda atau kabur; atau menghasilkan arti yang menunjukan tidak masuk akal atau tidak layaknya sebuah perjanjian internasional. Jika hanya membaca ketentuan yang termuat dalam Pasal 31 dan 32 dari VCLT kiranya belum dapat memberikan kejelasan, maka untuk itu perlu memperhatikan komentar-komentar dan pendapat tentang kedua Pasal ini pada saat pembahasannya. Dalam isi komentar Pasal 27 yang merupakan rancangan dari Pasal 31dinyatakan bahwa pasal ini didasarkan pada anggapan bahwa tekst perjanjian dipandang sebagai ungkapan otentik dari maksud para pihak, oleh karenanya titik tolak interpretasi adalah menjelaskan teks, bukan maksud dari para pihak mengenai tujuan perjanjian tersebut. ${ }^{35}$

Dengan demikian jika melihat kepada Pasal 31 dari VCLT terdapat tiga prinsip fundamental dalam penginterpretasian sebuah perjanjian internasional yaitu: interpretasi harus dilaksanakan atas dasar itikad baik yang merujuk langsung kepada asas pacta sunct servanda. Perjanjian yang akan diinterpretasikan menggunakan penginterpretasian dalam konteks textual, yaitu para pihak pembuat perjanjian memiliki maksud yang tampak dari arti yang lazim dari istilah-istilah yang mereka gunakan. Selanjutnya penginterpretasian perjanjian internasional menggunakan ordinary meaning yang dipandang sebagai maksud dari konteks isi perjanjian dan tujuan perjanjian tersebut. ${ }^{36}$

Dengan demikian perjanjian internasional yang membutuhkan interpretasi merupakan perjanjian yang memiliki masalah dalam penafsirannya. Hal tersebut seharusnya merupakan tugas dari ICJ untuk memberikan penafsiran terkait hal itu. Hal tersebut tertuang dalam Pasal 36 statuta ICJ yang berbunyi:

"The jurisdiction of the Court comprises all cases which the parties refer to it and all matters specially provided for in the Charter of the United Nations or in treaties and conventions in force. (2). The states parties to the present Statute at any time declare that they recognize as compulsory ipso facto and without special agreement, in relation to any other state accepting the same obligation, the jurisdiction of the Court in all legal disputes concerning: (a.) the interpretation of a treaty. "(ICJ Statute)

Bahwa kewenangan dari ICJ mencakup pada wewenang untuk memeriksa sengketa yang berkenaan dengan interpretasi suatu perjanjian dan ICJ sendiri pada dasarnya

35 Usmawadi Usmawadi, “Tinjauan Singkat tentang Interpretasi Perjanjian Internasional menurut Konvensi Wina Tahun 1969," Jurnal Hukum \& Pembangunan 18, no. 3 (19 Juni 2017): 288.

36 Ibid. 
menjalankan tugas interpretasi sesuai dengan pelaksanaan normal atributi hukum yang dimilikinya. ${ }^{37}$ Interpretasi merupakan salah satu hal yang paling sulit diselesaikan oleh ICJ dikarenakan interpretasi sendiri sangat berkaitan erat dengan hal yang mungkin bersifat fundamental bagi para negara peserta. $^{38}$

Pada tahun 1996 ICJ pernah mengeluarkan opini terkait legalitas dan ancaman penggunaan senjata Nuklir, ICJ menggunakan Pasal VI sebagai basis poin rujukan dalam merumuskan opini terkait tindakan yang dilakukan oleh NWS terkait penggunaan senjata nuklir bukan. Hanya sebagai tindakan nyata namun juga pemenuhan dalam Pasal VI dimaksudkan sebagai kewajiban final yang mengikat negara peserta dari NPT.

\section{Non-Proliferation Treaty 1968} NPT 1968 sebagai pernjanjian internasional yang menangani upaya-upaya pelucutan senjata nuklir sebagai antisipasi dari kemungkinan perang nuklir di masa depan memiliki tiga pilar utama yaitu:

1. Pada Pasal II NPT: setiap negara yang tidak memiliki senjata nuklir ATAU Non-Nuclear Weapon States (NNWS) tidak diperkenankan untuk memiliki / mengembangkan senjata nuklir. Serta pada Pasal III NPT: Negara-negara tersebut harus berkonsultasi dan memenuhi standar keamanan yang ditetapkan oleh International Atomic Energy Agency (IAEA).

2. Pasal IV NPT: Negara anggota memiliki hak untuk menggunakan energi nuklir untuk tujuan damai dan berjanji untuk bekerjasama dengan negara lain dalam penggunaan energi nuklir untuk tujuan damai.

3. Pasal VI: NWS dan negara lain (NNWS) berjanji untuk melakukan negosiasi dengan itikad baik mengenai langkahlangkah efektif untuk penghentian perlombaan senjata nuklir dan untuk pelucutan senjata nuklir dalam waktu yang sesingkat mungkin.

Nilai esensial dari NPT 1968 adalah pencegahan nuklir sebagai senjata, maka setiap negara yang memiliki nuklir atau ingin mengembangkan nuklir harus berkomitmen untuk bekerja sama dengan IAEA dalam konteks keselamatan nuklir. Sebagian besar NNWS memiliki komitmen secara politik untuk tidak memiliki atau mengembangkan nuklir sebagai senjata. Komitmen NNWS dalam hal ini bukan serta merta bergantung kepada protokol keamanan yang ditetapkan oleh IAEA, melainkan karena adanya dasar kepercayaan yang dibangun dalam proses verifikasi nuklir oleh IAEA. ${ }^{39}$ Hal tersebut menjadi nilai yang penting bagi negara-

37 Mauna, op.cit., hlm.142.

38 ULf Linderfalk, On the Interpretation of Treaties: The Modern International Law as Expressed in the 1969 Vienna Convention on the Law of Treaties (9781402063619) (EES0134/KLIBF08)-30. (Springer, 2007).

39 John Carlson, "Is the NPT Still Relevant? - How to Progress the NPT's Disarmament Provisions," Journal for Peace and Nuclear Disarmament 2, no. 1 (2 Januari 2019): 97-113. 
negara peserta NPT untuk berkomitmen tidak mengembangkan senjata nuklir.

Hingga hari ini NWS yang tercatat sebagai non anggota NPT ada sebanyak lima negara yakni: India, Israel, Iran Pakistan, dan Korea Utara (keluar di tahun 2003). Secara umum negara yang tercatat sebagai NWS ada sepuluh negara, lima diantaranya adalah negara yang tergabung sebagai peserta NPT1968, yakni; Amerika, Cina, Inggris, Perancis, dan Rusia. Di luar daftar negara-negara tersebut material nuklir yang ada dikategorikan sebagai penggunaan nuklir untuk tujuan damai sebagaimana yang dimaksudkan dalam Pasal IV NPT. ${ }^{40}$ Dalam hal posisi tawar jika dilihat dengan seksama NPT 1968 cendrung bersifat longgar terhadap NWS, sementara itu 180 negara lainnya yang berstatus NNWS diikat komitmen kuat untuk tidak memilki dan mengembangkan senjata nuklir, namun hal ini menimbulkan perselisihan yakni, NNWS ingin agar kewajiban dalam NPT dilakukan merata baik oleh NWS dan NNWS. ${ }^{41}$

Selanjutnya NPT 1968 memiliki korelasi yang erat antara Partial Test Ban Treaty (PTBT), Comprehensive Test Ban Treaty (CTBT), Nuclear Weapon Free Zones (NWFZs), Intermediate Range Nuclear Forces (INF), Strategic Arms Reduction Treaty (START), Strategic Arms Limitation Treaty (SALT), ${ }^{42}$ The Outer Space Treaty
1967 (the OST) DAN Moon Agreement 1979. Keseluruhan perjanjian-perjanjian tersebut merupakan upaya lanjutan konkrit terhadap apa yang dimaksudkan dalam arti esensial dalam NPT 1968 yaitu perlucutan senjata nuklir, karena kesemua perjanjian tersebut berbicara mengenai pelarangan penggunaan, pengetesan senjata nuklir baik di darat, udara, air, dan ruang angkasa.

Selanjutnya, dalam hal ini NPT memegang peranan paling penting karena merupaka core dari pencegahan bencana senjata nuklir, hanya saja yang menjadi perdebatan dalam NPT 1968 selama ini adalah kapan senjata nuklir dari NWS peserta NPT 1968 harus dilucuti, dikarenakan hingga saat ini kelima negara tersebut masih memelihara bahkan mengembangkan teknologi kesenjataan nuklir. Jika diperhatikan secara seksama dalam Pasal VI NPT 1968 tertulis:

"Each of the Parties to the Treaty undertakes to pursue negotiations in good faith on effective measures relating to cessation of the nuclear arms race at an early date and to nuclear disarmament, and on a treaty on general and complete disarmament under strict and effective international control."

Dalam teks tersebut menyimpan dua kunci utama yakni, pursue negotiations in good faith dan at an early date and to nuclear disarmament. Jika diinterpretasikan secara

40 Ibid.

41 Kiernan, Paul M., “'DISARMAMENT’ UNDER THE NPT: ARTICLE VI IN THE 21ST CENTURY." Michigan State International Law Review 20, no. 2 (2012): 20.

42 Merav Datan dan Jürgen Scheffran, "The Treaty Is Out of the Bottle: The Power and Logic of Nuclear Disarmament," Journal for Peace and Nuclear Disarmament 2, no. 1 (2 Januari 2019): 114-32. 
tekstual maka para pihak seharusnya dengan kemampuannya mengadakan negosiasi tentang pelucutan senjata nuklir dengan NWS dan NNWS dalam waktu yang sesingkatsingkatnya. Namun tentu saja bukan kejelasan mengenai interpretasi pada Pasal VI NPT yang didapat melainkan masuk kepada ambiguitas selanjutnya dari komentar ICJ di tahun 1996 dalam "advisory opinion on the legality of the threat or use of nuclear weapons" yang juga pada pengujiannya menggunakan Pasal VI NPT. Sayangnya seperti yang sudah dikatakan sebelumnya ICJ justru tidak banyak mengomentari Pasal VI NPT yang sesungguhnya esensial bagi usaha pelucutan senjata nuklir, ICJ hanya memberikan opinion yaitu: "exists an obligation to pursue in good faith and bring to a conclusion negotiation leading to nuclear disarmament in all its aspects under strict and effective international control." ${ }^{43}$

Dalam advisory opinion tersebut dapat dilihat jelas bahwa ICJ sendiri tidak memberikan kejelasan bagaimana usaha pelucutan senjata nuklir harus dilakukan sebagai bagian dari sebuah kewajiban sperti yang diamanatkan oleh Pasal VI NPT yang pada akhirnya meninggalkan sebuah ruang kosong/lacuna dalam konteks interpretasi. Selain itu advisory opinion tidak mengikat secara hukum bagi negara- negara. ${ }^{44}$
Selanjutnya, kata nuclear disarmament bisa memiliki dua makna di dalamnya yaitu, penghapusan senjata nuklir secara parsial atau secara total oleh negara anggota NPT1968. Namun dalam menyikapi hal tersebut juga harus dilihat pada kalimat pertama mengenai cessation jika dilihat secara komperhensif seharusnya makna dari kata pemberhentian dan perlucutan sejata nuklir akan lebih condong kepada perlucutan senjata nuklir secara total, karena baik NWS dan NNWS sama- sama memiliki kewajiban untuk tidak mengembangkan senjata nuklir, jika ini dimaknai secara jelas tidak mungkin akan ada senjata nuklir jika proses pengembangan teknologinya tidak berlanjut.

Merujuk kepada peraturan di atas bahwa setiap Negara tidak diperkenankan atau dilarang menggunakan senjata yang dapat menyebabkan rasa sakit yang tidak perlu, kerusakan jangka panjang, dan menyebabkan rusaknya lingkungan hidup, walaupun ketentuan yang mengatur pelarangan senjata nuklir tidak ada. ${ }^{45}$ Tetapi didalam protokol tambahan I sudah jelas untuk menggunakan senjata tersebut karena efek yang ditimbulkan adalah dilarang. ${ }^{46}$ Dalam opininya ICJ menjelaskan bahwa Pasal VI adalah mengikat secara hukum terhadap negara negara peserta dalam perjanjian tersebut. ICJ menuturkan bahwa Pasal VI memiliki sifat yang lebih

43 International Court of Justice, Legality of the Threat or Use of Nuclear Weapons: Advisory Opinion of 8 July 1996 (The Hague: International Court of Justice, 1996).

44 Ford, Christopher A. "DEBATING DISARMAMENT: Interpreting Article VI of the Treaty on the NonProliferation of Nuclear Weapons." The Nonproliferation Review 14, no. 3 (November 2007): 401-28.

45 "United Nations Institute for Disarmament Research (UNIDIR)" (Koninklijke Brill NV), https://doi. org/10.1163/1570-6664_iyb_SIM_org_39757, diakses 6 April 2020

46 Ibid. 
mendalam daripada hanya sekedar perjanjian yang dapat dinegosiasikan dimasa depan tetapi juga merupakan perjanjian yang harus dimaknai secara jelas (Pactum den Contrahendo). 47

\section{Kesimpulan}

Setelah diatas kita membahas bagaiamana pengintrpretasian dalam Pasal 31 VCLT dan bagaima praktik NWS dimasa kini, kita dapat menarik sebuah benang merah bahwa isi dari Pasal VI NPT menimbulkan sebuah interpretasi ganda terhadap katakata "an early date". Pengertian tersebut menimbulkan kerancuan kapan sesungguhnya negara peserta dari NPT tersebut harus benar-benar melenyapkan senjata nuklir nya. Praktik yang selama ini dilakukan oleh NWS tidak memperlihatkan kearah tersebut. Seperti contohnya Inggris, dan Amerika Serikat. Kondisi tersebut diperparah dengan perkembangan senjata nuklir yang dilakukan oleh India, Pakistan, Israel, Iran, dan Korea Utara, sehingga dapat mempengaruhi situasi keamanan global dimasa depan.

Jumlah hulu ledak yang menurun namun kualitas yang semakin meningkat, hal tersebut yang digunakan sebagai argumen bahwa pemenuhan itikad baik oleh NWS sudah terpenuhi. Permasalahan yang kini menghantui adalah bagaimana jika NPT ini hanya sebagai sebuah penahan sementara dari ancaman perang nuklir pada masa perang dingin. Bukan menjadi omong kosong jika dimasa depan NWS kembali menggunakan senjata nuklirnya secara agresif dengan dalih mempertahankan kedaulatannya dari serangan negara lain. Juga dalam bab sebelumnya efek yang ditimbulkan dalam penggunaan senjata nuklir akan menimbulkan efek penderitaan yang berkepanjangan yang dalam hal ini akan berpotensi melanggar Protokol Tambahan 1977.

NWS, dengan dalih apapun seharusnya bersepakat sedari pembuatan NPT bahwa tujuan utamanya haruslah untuk memelihara perdamaian dan keamanan dunia dari munculnya perang nuklir. Inti dari NPT ialah menciptakan dunia yang aman dan damai bebas dari penggunaan senjata nuklir demi keberlangsungan umat manusia. Kata-kata "an early date" seharusnya jika ditelaah secara per analogiam sudah memunculkan sifat yang harus dicapai dengan sesegera mungkin. Kata sesegera mungkin tersebut idealnya tidak dilakukan hingga berlarutlarut dan menjadikannya ad riddiculum yang membuat NPT seakan-akan kehilangan esensinya yang utama.

Selanjutnya, jika merujuk kepada pembahasan mengenai kasus RKM dengan Inggris yang pada akhirnya ditolak karena salah satunya adalah lack of jurisdiction memantik kontroversi, seharusnya ini adalah saat yang tepat bagi ICJ untuk menelaah kembali Pasal VI NPT berdasarkan aktivitas NWS saat ini untuk kepastian akan perdamaian dan pencegahan bencana nuklir di masa depan, setelah ICJ "menghilangkan" momentum penafsiran pada permohonan advisory opinion di tahun 1996. 


\section{DAFTAR PUSTAKA}

\section{Buku}

Aust, Anthony. Modern Treaty Law and Practice. Second Edition.

Cambridge: Cambridge University Press, 2007.

Komar, Mieke, Beberapa Masalah Poko Konvensi Wina 1960 Tentang Perjanjian Internasional. Diktat S1 dan S2 Fakultas Hukum UNPAD. Bandung Kusumaatmadja, Mochtar, dan Etty R. Agoes. Pengantar Hukum Internasional. Kedua. Bandung: Pt. Alumni, 2012.

Mauna, Boer. Hukum Internasional Pengertian Peranan dan Fungsi dalam Era Dinamika Global. Edisi Kedua.

Bandung: Pt. Alumni, 2015.

ULf Linderfalk. On the Interpretation of Treaties: The Modern International Law as Expressed in the 1969 Vienna Convention on the Law of Treaties (9781402063619) (EESO134)

KLIBF08)-30. Springer, 2007.

\section{Jurnal}

Carlson, John. "Is the NPT Still Relevant? - How to Progress the NPT's Disarmament Provisions." Journal for Peace and Nuclear Disarmament 2, no. 1 (2 Januari 2019): 97-113.

Datan, Merav, dan Jürgen Scheffran. "The Treaty Is Out of the Bottle: The Power and Logic of Nuclear Disarmament." Journal for Peace and Nuclear
Disarmament 2, no. 1 (2 Januari 2019): 114-32.

Drummond, Brian. "UK Nuclear Deterrence Policy: An Unlawful Threat of Force." Journal on the Use of Force and International Law 6, no. 2 (3 Juli 2019): 193-241.

Dunn, Lewis A. "Negotiating and Sustaining the Non-Proliferation Treaty: Challenges and Lessons for US-Russia Cooperation." Adelphi Series 56, no. 464-465 (November 2016): 117-34.

Ford, Christopher A. "DEBATING DISARMAMENT: Interpreting Article VI of the Treaty on the Non-Proliferation of Nuclear Weapons." The Nonproliferation Review 14, no. 3 (November 2007): 401-28.

Gibbons, Rebecca Davis. "The Humanitarian Turn in Nuclear Disarmament and the Treaty on the Prohibition of Nuclear Weapons." The Nonproliferation Review 25, no. 1-2 (2 Januari 2018): $11-36$

Kiernan, Paul M. "'DISARMAMENT' UNDER THE NPT: ARTICLE VI IN THE 21ST CENTURY." Michigan State International Law Review 20, no. 2 (2012): 20.

Kristensen, Hans M. "Despite Rhetoric, US Stockpile Continues to Decline." Federation of American Scientist, 2018. https://fas.org/blogs/security/2018/03/ stockpile-reduction/. 
Kristensen, Hans M., dan Matt Korda.

“Tactical Nuclear Weapons, 2019."

Bulletin of the Atomic Scientists 75, no.

5 (3 September 2019): 252-61.

—. "United States Nuclear Forces, 2020." Bulletin of the Atomic Scientists

76, no. 1 (2 Januari 2020): 46-60.

Rabinowitz, Or. “'When Pigs Fly': Britain,

Canada and Nuclear Exports to Israel, 1958-1974." Diplomacy \& Statecraft 30, no. 4 (2 Oktober

2019): 707-28.

Simon, David. "ARTICLE VI OF THE NON-PROLIFERATION TREATY IS A PACTUM DE CONTRAHENDO AND HAS SERIOUS LEGAL OBLIGATION BY IMPLICATION." Journal of Internationa Law \& Policy II (2005).

Usmawadi, Usmawadi. "Tinjauan Singkat tentang Interpretasi Perjanjian Internasional menurut Konvensi Wina Tahun 1969." Jurnal Hukum \& Pembangunan 18, no. 3 (19 Juni 2017): 288.

\section{Naskah Internet}

France, Agence. "The Guardian 'Bikini Atoll Nuclear Test: 60 Years Later and Islands Still Unliveable." News Magazine. The Guardian, 2014. https://www. theguardian.com/world/2014/mar/02/ bikini-atoll- nuclear-test-60-years.

International Committee of Red Cross. "Protocol Additional to the Geneva
Conventions of 12 August 1949 and relating to the Protection of Victims of International Armed Conflicts (Protocol I), 8 June 1977." Treaties, States Parties and Commentaries, t.t. https://ihldatabases.icrc.org/ihl/WebART/470750070?OpenDocument.

Ministry of Defence. "Policy paper 2010 to 2015 government policy: UK nuclear deterrent." Government of UK, 2015. https://www.gov.uk/government/ publications/2010-to-2015government-policy-uk-nucleardeterrent/2010-to-2015-governmentpolicy-uk-nuclear-deterrent.

Neil, Jain. "UK Nuclear Program." Coursework for PH241, Stanford University, Winter 2017. Stanford: Stanford University, 2017 http://large. stanford.edu/courses/2017/ph241/ jain1/.

NTI. "U.S Nuclear Overview." Nuclear Threat Initiative, 2019. https://www. nti.org/learn/countries/united-states/.

"The UK's nuclear deterrent: what you need to know," 2018. https://www.gov.uk/ government/publications/uk-nucleardeterrence- factsheet/uk-nucleardeterrence-what-you-need-to-know.

The Editor of Encyclopedia Britannica, "Treaty of Tordesilhas", https://www. britannica.com/event/Treaty-ofTordesillas.

"United Nations Institute for Disarmament Research (UNIDIR).” Koninklijke 
Brill NV. https://doi.org/10.1163/15706664_iyb_SIM_org_39757. Diakses 6 April 2020.

\section{Putusan ICJ}

International Court of Justice. Legality of the Threat or Use of Nuclear Weapons: Advisory Opinion of 8 July 1996. The Hague: International Court of Justice, 1996.
"Obligations Concerning Negotiations Relating to Cessation of the Nuclear Arms Race and to Nuclear Disarmament (Marshall Islands v. United Kingdom)." Summary of the Judgment of 5 October 2016. The Hague: International Court of Justice, 5 Oktober 2016. 